\title{
Exploring Trust in Digital Civics
}

\author{
Eric Corbett Christopher A. Le Dantec \\ Georgia Institute of Technology \\ Atlanta, GA. USA \\ \{ecorbett, ledantec\}@gatech.edu
}

\begin{abstract}
Digital civics research seeks to understand how technology can create new forms of relationships and services between public officials and citizens in governance. To accomplish this, design in digital civics emphasizes the importance of relationships based on dialogue, empowerment, and participation; all of which are contingent upon the existence of trust. Currently, however, these relationships are most often characterized by entrenched distrust which problematizes opportunities for dialogue and participation. In this paper, we explore how design might support trust in the relational aims of digital civics. To do so, we led 13 public officials in a large US city through a design-based inquiry centered around the role of trust in their various efforts to engage communities. In our findings, we discuss four strategies for supporting trust in digital civics.
\end{abstract}

\section{Author Keywords}

Digital Civics; Trust; Community Engagement

\section{ACM Classification Keywords}

H.5.m. Information interfaces and presentation (e.g., HCI): Miscellaneous;

\section{INTRODUCTION}

Digital civics is a research agenda interested in how to bring about "new configurations of government and citizenry that is relational rather than transactional" [40]. The emphasis on relational civic encounters "enables us to begin to view governments (local or national) as composed through relations with constituents" [1]. Thus, rather than focusing on how design might make government efficient (egovernment), or make existing modes of democratic participation more accessible (digital democracy), design in digital civics focuses on how to create relationships in participatory experiences between public officials and citizens based on mutual learning, empowerment, and cocreation $[1,34]$.

Permission to make digital or hard copies of all or part of this work for personal or classroom use is granted without fee provided that copies are not made or distributed for profit or commercial advantage and that copies bear this notice and the full citation on the first page. Copyrights for components of this work owned by others than ACM must be honored. Abstracting with credit is permitted. To copy otherwise, or republish, to post on servers or to redistribute to lists, requires prior specific permission and/or a fee. Request permissions from Permissions@ acm.org.

DIS '18, June 9-13, 2018, Hong Kong

(C) 2018 Association for Computing Machinery.

ACM ISBN 978-1-4503-5198-0/18/06 ...\$15.00

https://doi.org/10.1145/3196709.3196715
The turn to relational encounters presented by digital civics is timely given the widespread distrust that currently characterizes interactions between public officials and citizens throughout many modern democracies $[10,45,47]$. In fact, this distrust now is so pervasive that "it is a given and perhaps even a framework that conditions all possible [civic] relationships" [31]. Moreover, despite the importance that trust plays in civic institutions, and its role in the digital systems we build to support and access those institutions, trust is often bracketed out as either an externality to the design space or assumed to be a built-in attribute of technology itself [19]. It is only more recently that trust has become a first-order concern of research and design for HCI in this space [12,28].

To further explore trust as a design value in digital civics, we conducted a workshop with municipal officials from a large US city. The goal of the workshop was to develop design insights for digital civics drawn from how these officials view the role of trust and technology in the work of community engagement. We focus exclusively on municipal officials in this study to better understand the role of trust within the organizational and institutional arrangements of governing and providing public services. Our study helps expand recent work in HCI that tends to approach digital civics exclusively as citizen-to-public official; an unnecessarily narrow view given the importance of buy-in and support of public officials as a key factor in the long term success of digital civic systems $[43,44]$.

Our findings provide four strategies for supporting trust in digital civics: historicizing engagement, focusing on experience, mediating expectations and preserving institutional relationships. Taken together, these strategies provide insight into how technology should be designed to support trust in the work of community engagement. Through our analysis of the workshop material, we reveal several tensions that need to be confronted to advance digital civics. These include: supporting the needs and challenges public officials face in their efforts to engage communities; and on the other, achieving the transformative, democratic goals the research ascribes to. We end by discussing how focusing on the affordances derived from the four strategies we developed could address these tensions.

\section{BACKGROUND}

There are two elements that setup the areas of focus for this paper: the first is the turn to digital civics as a way to reimagine civic systems to support relational interactions; the second is taking on trust as an under-studied attribute of 
systems that is needed in order to support action in the face of imperfect knowledge, unequal power relations, and political conflict.

\section{Digital Civics}

In a move beyond the privileged and professionalized versions of democratic participation, digital civics seeks to understand and design technologies for a wider range of civic interactions and experiences. There are two key elements to digital civics. The first is a turn to participatory systems described by McCarthy and Wright as enabling "an open, empathic, and critical questioning relationship... [that] construct[s] new imaginaries through mutual learning" [34]. By engaging in conflicts and counter narratives, digital civics enables a kind of shared learning and shared ownership about issues and their resolution [15,22]. Importantly, there is an inclination to examine civic transformation-institutional or community centered - as incremental rather than immediate.

The incremental impact of participatory systems leads to the second element of digital civics: a focus on relational interaction $[8,40,46]$. By attending to the relations that underpin our civic lives, we open the design space to include modes of identity- and place-making [16,22], as well as sites of advocacy and activism [2,14,15]. The focus on relational interactions reframes civic encounters such that government services are created in the doing that happens between officials and citizens and not simply delivered to citizens. By focusing on the co-created outcomes of civic life, we can begin to view governments (local or national) as composed through myriad relations with constituents, and it is precisely these relations that matter most in day-to-day civic life $[4,8]$.

By looking beyond the narrow scope of rational deliberative decision making, digital civics confronts governance-and technology's role in governance - not as a means to more perfect knowledge-via sensors, databases, and algorithms - but as interactions based in power dynamics, social and political capital, and local histories. Across the different kinds of interactions of place making [15], identity building [22], and fostering civic engagement, the conditions of trust (or its absence) plays a crucial role [1,14]. Yet trust, as a first-order concern for design, has remained under examined, particularly as it relates to institutional processes and historic experiences with government in HCI.

\section{Trust and Governance}

While trust is a vital component to enabling cooperative action in situations of risk [5], the role of trust in community engagement is less clear: some scholars suggest distrust from citizens provides a healthy and necessary check against the power of public officials and serves as the primary motivator for engagement [25]; while others argue that trust is essential to enabling and facilitating engagement [41]. This debate stems from how cooperative work in political relationships are inherently problematic for trust as "the mere fact that a social relationship has become political throws into question the very conditions for trust" [54:1]. Those conditions are predicated on a need to overcome uncertainty and risk.
Trust, as we use it throughout this research, is a mechanism for dealing with uncertainty. Without uncertainty, there would be no risk; no risk would obviate the need for trust [37]. For this reason, trust comes into play only when the risk presented by a situation cannot be reduced entirely. The process of trust is best described as how one comes to form expectations that allow the "leap" over uncertainty [38]. The mechanisms that enable that process derive from "distinct cognitive, emotional, and behavioral dimensions which are merged into a unitary social experience" [32]; this then allows for the "reduction of complexity, [and] discloses possibilities for action which would have remained improbable and unattractive without trust" [33].

In this regard, the question of how to trust is the essence of political relationships where compromises and actions can only ever be made with partial knowledge and varying degrees of risk. Further, it is within the larger debate of whether engagement is motivated by trust or by distrust that design in digital civics finds itself.

Clearly, digital civics' focus on participatory and relational interactions between public officials and citizens is preconditioned by the current environment of distrust $[41,42,45]$. How will (or should) design in digital civics contend with this condition? In prior work within the same municipal setting, we established a conceptual framework that describes how trust develops as a process with distinct stages: initiating trust, building trust, and finally retaining trust [12]. The degree of trust increases in each stage, creating evermore possibilities for cooperative actions between public officials and citizens. Moving across the stages is done through a collection of practices we called "trust work." This work is performed by public officials in order to overcome barriers to trust in both interpersonal and institutional relationships with their constituencies.

In completing our initial research into trust and community engagement, we recognized that the trust work performed by public officials is at best poorly supported in the current landscape of digital technology and at worst completely incompatible. To begin to address this gap between the tools municipal official have to do the work of community engagement, and the need to directly respond to different stages of trust, we designed a workshop to specifically explore how trust might be operationalized to support the work of community engagement in digital civics. In doing so, we are adding to the larger understanding of how to build systems to bring government and citizens together (e.g., ([6,28,29]).

\section{WORKSHOP STRUCTURE}

In order to explore trust as a design value in digital civics, we organized a workshop with public officials. We recruited 13 public officials representing 12 departments/organizations from our home municipality-a large US city with a populous urban core and a much larger metro region (Table 


\section{Department/Organization}

$\begin{array}{ll}\text { Public Health NGO } & \text { P1, P2 } \\ \text { Parks and Recreation } & \text { P3 } \\ \text { City Planning } & \text { P4 } \\ \text { Watershed Management } & \text { P5 } \\ \text { Public Works } & \text { P6 } \\ \text { Immigrant Affairs } & \text { P7 } \\ \text { Economic Development } & \text { P8 } \\ \text { Public Safety } & \text { P9 } \\ \text { Beltline Partnership } & \text { P10 } \\ \text { Parks Advocacy } & \text { P11 } \\ \text { Public Health UNIVERSITY } & \text { P12 } \\ \text { Regional Planning } & \text { P13 }\end{array}$

Table 1. List of departments/organizations and participant code.

1). We were intentionally broad in recruiting participants looking for a wide representation from the breadth of municipal entities that exist across the city. The workshop ran

concurrently in three sessions over the course of two weeks. Each session was approximately two hours and took place on our campus. One researcher recorded ethnographic field and photo documentation while the lead author ran the workshops. We also audio recorded the workshops which we then partially transcribed to provide additional fidelity to key exchanges identified in our ethnographic notes.

The workshop was designed around the conceptual elements of trust in community engagement we developed in previous work [12]. The first of these concepts were the 'trust circles' - canvases we designed to represent the three stages of how trust is developed in the work of community engagement (Figure 1). The workshop activity required participantsworking individually - to think through each stage of the trust process - initiating, building, and retaining-by matching together three forms of prompts: barriers, actions, and technologies (Table 2). We designed the trust circles to force participants to decompose the process of trust into the stages represented on the canvas; building on our prior work we understood that each stage required different responses to the provided prompts. Each participant had their own trust circle, individual sets of the prompts, and blank cards they could use to introduce new prompts as they saw fit.

At the center of each trust circle was a goal the participant identified as part of their current work (Figure 1). The goals pursued during the workshop ranged from specific project outcomes to more general organizational imperatives. P1, P2 and P13 pursued goals that aimed to improve different communities they work within: P1 and P2 each had goals tied to specific health interventions; P13 sought to improve communities across the city by facilitating access to the technical planning resources his organization provides. P3,
P6, P7 and P9 pursued goals aimed at expanding institutional relationships with different segments of the community: P3 sought to connect the department with new constituents; P6 with millennials to improve the city's recycling initiatives; P9 with minority and underserved communities; P7 with immigrant communities. P4 and P11 pursued goals aimed at increasing community input into decision making processes: P4 through coordinating the city's neighborhood planning units which provide a mechanism for communities to provide input on zoning, land use and city ordinances; P11 by facilitating community led master planning processes for city parks. P5 and P8 pursued goals to improve their department's communication with communities: P5 wanted to make sure customers understood how to interact with the department for billing and service requests; P8 wanted to provide a better public understanding of what her agency is and its purpose. P10 and P12 pursued goals to create community ownership of department initiatives: P10 wanted to better involve communities in customizing how his agency's infrastructure project would impact neighborhoods; P12 pursued this goal generally as it is vital to the sustainability of initiatives across all his agency's work.

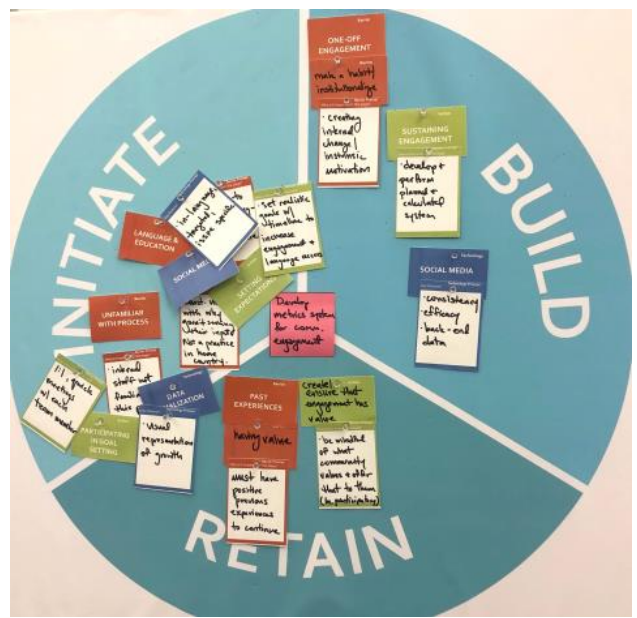

Figure 1. Completed trust circle. The circle is broken down into the three stages of the trust process: Initiate, Build and Retain. Each participant had their own trust circle with their goal placed in the center on the pink post-it

These goals grounded the activity so that participants could link specific challenges they were facing with the different stages of trust, the barriers to moving forward, and the actions they were or could be taking to advance toward their goal. Once the goals were established, participants pinned the different prompts to their trust circles, adding descriptive detail that further explained why they selected the prompt. At the end of each stage we brought the participants together to share their selection of barriers, actions, and technologies to the group.

The barrier prompts (Table 2) included 14 barriers to trust that represented the most salient forms of risk in community engagement identified from our previous work [12,13]. 
Participants would select the barriers they felt were important to address in in order to develop trust to the next stage - from initiating to building, and from building to retaining. The barriers general issues such as misinformation, fear of change, language and education while others were more

mixture between those that were familiar and unfamiliar. In this way, we hoped to elicit selections that were both pragmatic as well as those that were explorative and future orientated.

In short, during the workshop each participant worked individually on reaching their goal by thinking through each

\begin{tabular}{|c|c|c|}
\hline Barriers & Actions & Technologies \\
\hline $\begin{array}{l}\text { Speed of Progress; Misinformation; } \\
\text { Cycles of Leadership; Perception of Equity; } \\
\text { Input Doesn't Matter; Language and Education; } \\
\text { Availability for Engagement; Past Experiences; } \\
\text { Accessibility; Sense of Voicelessness; } \\
\text { Unfamiliar with Process; One-off Engagement; } \\
\text { Out of the Loop; Fear of Change }\end{array}$ & $\begin{array}{l}\text { Being Present; Setting Expectations; } \\
\text { Sharing Decision Making; Sustaining } \\
\text { Engagement; Listening; Educating } \\
\text { Community; Participating in Goal Setting; } \\
\text { Managing Expectations; Meeting people } \\
\text { where they are; Raising Awareness }\end{array}$ & $\begin{array}{l}\text { Mobile App; Website; Survey; Virtual } \\
\text { Meeting; Drone; Data Visualization; } \\
\text { Broadcast Media; Group Messaging; } \\
\text { Crowd Sourcing; Hologram; Open Data } \\
\text { Portal; Smart City; Blog; Virtual Reality; } \\
\text { Social Media; Electronic Polling; Text } \\
\text { Messaging; Data Visualization }\end{array}$ \\
\hline
\end{tabular}

Table 2. List of design prompts: 14 Barriers; 10 Actions; 18 Technologies

specific to trust in the context of community engagement and municipal government such as speed of progress, one-off engagement and cycles of leadership. We provided general descriptions of the barriers but encouraged participants to interpret them openly in the context of their work.

Similar to the barriers, we developed 10 action prompts (Table 2) also identified through previous work [12]. These actions included practices public officials would commonly describe as important to building trust in community engagement (described as "trust work" in [12]). Participants would select actions they felt could address the barriers pinned to the trust circle. Like the barriers, each of the actions were briefly described while allowing an open, flexible interpretation. For instance, the action educating community could be carried out in many ways: formal training or workshops, informal conversations, or website information.

Finally, there were 18 technology prompts (Table 2). We selected a wide range of technologies in order to provide flexibility for various municipal work domains represented by our participants. In selecting the technologies, we wanted a mixture between those that were conventional and familiar (website, survey, text messaging), to existing but new (virtual meeting, crowd sourcing), to the more future orientated, distant technologies (holograms, drones, smart cities). Participants selected technology prompts based on how the technology could augment their trust processes by either improving how an action was performed or helping to address a barrier.

As an example of the whole workshop activity, a participant might choose the barrier misinformation to describe the skepticism citizens might feel toward official communication channels. In response to that barrier, the participant could choose some form of action, for instance educating community as a remedy. Pushing that remedy into technology, they might choose virtual meeting to mediate the action educating community in order to address the barrier misinformation. Throughout the workshops we encouraged participants to approach technology selections that were a stage of the trust process represented by the trust circle (Figure 1) matching the barriers they felt were relevant- to actions that would address those barriers-and finally technologies they have access to (or envision having access to) that would aid their process (Table 2). This allowed us to get a wide view of how public officials across a range of municipal roles address barriers for trust in their goals of community engagement.

\section{Analysis}

The data collected from the workshop, comprising the selections of barriers, actions, technologies, goals, field notes, photos and audio, were subject to inductive analysis [36] in order to connect the nascent strategies for addressing trust that developed across the different workshop instances. We decided to organize our analysis around the barrier prompt selections as these were the central material of the workshop activity. We started by first identifying the most frequent barrier prompts selected in the workshop. These were (in descending order of frequency): speed of progress, past experiences, unfamiliar with process, misinformation, one-off engagement and cycles of leadership. We then looked for strategies in how these barriers were addressedinterrogating the data by asking and comparing: What actions were selected and why? How did the technologies factor in? How were selections differentiated by participant domain as well as goals? The common strategies that emerged form the foundation for how we can move systems design forward when considering the need to account for and develop trust between institutional actors - here city officials and departments - and individuals outside those institutions - i.e. city residents.

\section{DESIGN STRATEGIES}

We present four strategies developed by analyzing the themes in how barriers, actions and technologies (Table 2) were aligned to develop trust during the workshop: historicizing engagement, focusing on experience, mediating expectations and preserving institutional relationships. These strategies are meant to provide design advice drawn from how public official view the role of trust and 
technology in the work of community engagement. Each of the strategies focus on a particular barrier: historicizing engagement addresses the barrier of past experiences; focusing on experience confronts the barrier of one-off engagement; mediating expectations is a way to address the barrier of speed of progress; preserving institutional relationships helps bridge the barrier of cycles of leadership.

Each of the strategies also falls into a particular stage of the trust process. First, historicizing engagement is important to the initiating stage as it addresses past experiences that need to be acknowledged and then adjusted to. Next, focusing on experience falls in between the initiating and building stages as it addresses how to provide an experience of engagement that will lead to ongoing interactions that further build trust. Then, mediating expectations falls in-between building and retaining stages as it addressed how to maintain momentum to sustain trust over time. Finally, preserving institutional relationships is most relevant to the retaining stage as it addresses how relationships established over the course of the trust process can be preserved for future work.

\section{Historicizing Engagement}

Historicizing engagement is a strategy for addressing instances of the barrier past experiences which impact the ability to develop trust in the present. While trust as process is future orientated, it is forged upon past experiences which serve as material in the process of forming expectations [37]. Thus, a key part of trust as a process is overcoming fear and doubt that may stem from negative past experiences. In this way, past experience is the primary, fundamental barrier for trust. For this reason, we began with this strategy as it initiates the trust process and thus sets the stage for the remaining three strategies to unfold during the building and retain stages.

The barrier of past experiences manifested in a variety of contexts and forms in the workshop. P5 in watershed management had to contend with the past experiences of poor responsiveness to issues with service. Responsiveness was also the challenge with P9 in public safety which he described: "many people have past experiences where crimes have been committed against them or family and friends that they feel were not taken seriously." For P10 in infrastructure development, past experience was the history of broken promises of neighborhood revitalization in minority communities. For P12 in community health, it was the history of negligence that underserved communities felt towards outsiders who alleged to work benevolently but in the end used engagement to further their own agendas.

There were two key concerns that underlie historicizing engagement: engaging the past and altering engagement in a manner that is historically aware and appropriate. First, there is the work of engaging the past which was primarily about developing empathy with it: both P9 and P10 selected the actions 'meeting people where they are' and 'listening' to achieve this. P9 described this work as the need to build understanding: "Take time to get a handle at how the community lives. Understand what's normal and what's not." P10 felt these actions would build relationships by establishing a presence with (and within) the community: "[making] yourself present, available and engrained in the community." For the technology prompts, both P9 and P10 selected 'social media' and 'surveys' to help learn, listen and connect. In this way, the technology selections augment the actions: social media provides a way of meeting people where they are (online) and surveys provide a structured way to listen.

The second key concern of this strategy, altering engagement, was described by $\mathrm{P} 12$ as the need to be flexible in engagement: "being prepared to go slower and/or move away from the agenda" when necessary. In this case, P12 is aware that flexibility engenders trust-allowing agency to express concerns with the speed or direction of a process. This is especially important given the history of experiences in the community he is working in. He selected the technology 'electronic polling' as way to feel when and where flexibility might be needed by gauging feelings periodically throughout an engagement process. He thought electronic polling provided a safe, comfortable way for people to express feelings that they otherwise might not be willing to in one-on-one or larger group meetings. For P5, altering engagement was a matter of increasing responsiveness by following up and sustaining communication patterns. She selected the technology 'open data portal' to compliment responsiveness by increasing visibility and openness of her department's processes. For P10, altering engagement was expressed as a sensitivity towards decisions about technology use in engagement. He selected the action 'sharing decision making' which he felt was important to address the barrier 'perception of equity'. This action and barrier were important for his department's goal of involving communities - some which are very uneasy due to the history of inequity in development work in the city - in customizing how development would impact neighborhoods. P10 initially selected the technology 'crowdsourcing' to augment his action; however, upon reflection he later altered this selection by adding in paperbased surveys because, "everything we do has to be mirrored in a non-technology way too." In this case, P10 is sensitive to the history of this community being left out of conversations in development. As a result, he is careful not to exacerbate this history by introducing technology that may be inappropriate to the level of access, familiarity, and comfort. So, while crowdsourcing might be well suited as medium to achieve shared decision-making care must be taken that it does not present a new barrier while doing so.

The key affordance of this strategy is history-how to attend to the memories, emotions and experiences of the past that can create barriers for trust in the present. Due to the idiosyncrasies of history, the strategy of historicizing engagement is complex and requires nuanced response; nonetheless, there are some key takeaways for digital civics that arise in the ways in which past experiences are 
addressed. First, the technologies used highlight the importance of increasing the flow of communication from resident-to-public official. While altering engagement suggest systems that are flexible and adaptable to the needs of past experiences rather that rigid or primarily concerned with making engagement more efficient. On the point of efficiency, there is the tension between on one hand how public officials doing the work of engagement are typically overworked and under staffed therefore increasing the efficiency of engagement work is rightly desirable. On the other hand, historicizing engagement may require work to slow down and agendas to be altered thus reducing efficiency.

\section{Focusing on Experience}

While the previous strategy focuses on conditions of the past that form barriers for initiating trust, focusing on experience addresses conditions of the present that must be addressed in order build trust further. The primary barrier this strategy addresses is one-off engagement. This barrier arises from inconsistency in community engagement which is problematic for trust - as ongoing, continuous and frequent interactions are its building blocks [38]. The most prevalent cause of one-off engagement were issues with the experience of engagement that can prevent citizens from engaging in an ongoing manner. For instance, P11, whose goal was increasing public input by facilitating community-led master planning processes for city parks, believes the experience of engagement is typically too narrow as citizens are given limited agency in the larger picture of how decision-making process play out. He believes this leads citizens to devalue engagement-resulting in one-off engagements that ultimately reduce input because citizens often participate once but never return. In this case, P11 chose the action 'educating community' by creating citizen academies which would be trained (and eventually train others) with an expanded view of participation in the planning process. He selected 'blogs' as technology that could amplify the reach of these academies by offering citizen presentations on those blogs.

P4 also pursues the goal of increasing input through his department's work of coordinating the city's neighborhood planning units (NPUs) that provide a mechanism for communities to provide input on zoning, land use and city ordinances. P4 deals with the inconsistency of citizens experiences in participating in the NPU system as the nature of these units vary significantly based on current leadership and active members. P4 selected the action 'sustaining engagement ' which he described as continuing to develop an understanding of the different pain points for citizen experiences in NPUs. He selected the technology 'electronic polling' as way to gather data and inform improvement work in an efficient and convenient manner.

P13 wanted to address the experience of engagement feeling transactional: "agencies can get a bad rap for only engaging communities when they must put together a periodic plan for funders, etc. Agencies can been seen as disingenuous or inauthentic if they only engage communities in these 3 or 4 year intervals." Transactional experiences stem from when engagement occurs only to satisfy institutional needs rather than the needs for ongoing relationships with the communities that they serve. P13 selected the action 'educating community' as way to provide a more regular, direct linking with residents to understand their needs and concerns. He selected the technology prompt 'virtual meeting' as a way to mitigate the resources strain that his action selection would introduce.

The key affordance of this strategy is the experience of engagement; however, as Asad et al noted "community engagement is to cities what user experience is to computing: it signifies a large and multi-faceted category that simultaneously speaks to general qualities of interaction and to specific ways of doing that interaction" [1]. Thus, given the inherent variability of experiences - this strategy resists prescriptive implications for design of trust in digital civics. Rather, than prescriptions, the value of this strategy is simply in how it calls focus to the quality of experience in engagement which can be overlooked in comparison to other aspects such as empowerment, access, and social justice. While these are important nonetheless (as both outcomes and conditions of engagement), this strategy suggests a holistic view of the conditions that affect the quality of the "user experience" overall.

\section{Mediating Expectations}

Having addressed issues of the past and present in the previous two strategies, we move to the strategy mediating expectations which focuses on issues with future expectations. Conceptually, this strategy falls into the building stage of trust. The primary barrier this strategy addresses is speed of progress which refers to the speed in which the results of the work of community engagement come to fruition. Speed of progress can either be too slow, or too fast; both of which are problematic for trust. For P9 in public safety, his goal of expanding relationships with minority and underserved communities is problematized by the speed of progress being too slow in issues like systemic neighborhood crime or ongoing police accountability. For planners like P3 and P10, speed of progress can be too fast when it comes to introducing change to the built environment causing fear of change. In both cases, deferential expectations of speed (what one considers a reasonable timeframe) is the issue.

Expectation is what enables trust - trust is the process of how one comes to form positive expectations in the face of uncertainty [38]. In this way, expectation and time are the primary elements of trust. These elements are interlocked as the strength of trust (or distrust) at any given point is dependent upon sustaining expectations. In the work of community engagement this means that trust will fluctuate over the course of an engagement process - as the momentum of expectations meets the friction of the passage 
of time. This was evident for P13 in regional planning where projects run for many years with multiple moving parts and contingencies that results in oscillating momentum. This was also the case for P10 whose work in infrastructure development operates on a timescale of decades whilst the economic, social and cultural ramifications of the work do not (and may not ever) align with the physical manifestations of the work. This makes expectations difficult to sustain as P10 describes, "[it] can be a frustration that change isn't coming fast enough..."

We developed the strategy mediating expectations based upon the two key concerns in how speed of progress was addressed: shaping expectations and maintaining momentum. The first concern of this strategy shaping expectations starts with providing a basic understanding of the factors that impact speed of progress so that expectations can be formulated. An example of this was in how P5 in watershed management selected the action 'educating community' which meant making sure residents had at least a basic awareness of the processes of her department: "it is important the public know that we do have a process for services offered... sometimes they just don't know... they may just reach out to their council member on Twitter rather than call our hotline." After expectations are in place, the second concern comes into play - as it then becomes important to engage regularly as a way to maintain momentum. Illustrating this second concern, P13 in regional planning selected the action 'sustaining engagement' which is important, "because it helps citizens track with the progress of projects that cannot be seen at a glance. It also helps them better understand the process of funding and implementation." Here, sustaining engagement not only does the work of maintaining momentum but also helps to expand understanding of the process as it develops over time.

The technology prompts selected in this strategy fell into two categories: visualizing processes and facilitating ongoing conversation. Both $\mathrm{P} 3$ and $\mathrm{P} 9$ selected technologies that would mediate expectations through visual representation. P3 selected onsite 'holograms' to show final plans or where a plan is at in order to help with the action 'setting expectations.' He selected 'data visualization' to help 'sustain engagement' which was using data visuals to update and educate in a way that would be easy to understand and remember. Likewise, P9 selected 'data visualization' to help momentum by, "being able to visualize what the progress is... getting the community hope... something to look forward to."

P5, P6, P10 and P13 all selected technologies to facilitate ongoing interactions. For P5 and P6, (both in service providing departments) this took the form of custom 'mobile apps' for their departments that would mediate expectations through providing a communication channel that is real-time and customizable. P6 described the benefits of this as, "Mobile app may allow ratepayers the ability to interact with department in real-time see status of issues, more effectively pay bill (this helps with speed of progress)." P10 selected 'text messaging' to facilitate ongoing interactions because it is, "digital divide friendly...even if you don't have smart phone to use our app." Whereas P13 selected 'blogs', "because it allows anyone to read about the progress of projects at any time. It also allows comments and $Q \& A$ features so learning can take place."

The key affordance of this strategy is expectation which is mediated by altering perception, experience and interaction. Expectation is vital for trust-as trust is future orientatedproviding the suspension of doubt that enables one to pursue actions toward a desired future [33]. The challenge for trust in community engagement is in how to sustain ongoing work necessary to reach some desired future in the face of uncertainty and setbacks.

\section{Preserving Institutional Relationships}

The last strategy, preserving institutional relationships, falls into the retaining stage of the trust process as is it is concerned with the ways in which trust can be retained in relationships over time. The primary barrier this strategy addresses is cycles of leadership. Cycles of leadership refers to the cyclical nature of civic relationships: how contact points on both sides of the relationship are constantly shifting making trust difficult to hold in place over time. On the government side, this barrier reverberates through the political cycles of elected officials moving in and out of power, who then appoint new department leaders who in turn hire new employees.

We developed the strategy preserving institutional relationships based upon the concern of preservation that was central to how cycles of leadership were addressed. Preservation was pursued by extending the focal point of institutional contact beyond top leadership in such a way that preserves relationships through cycles. The action 'sustaining engagement' is a key component of this strategy as P8 describes, "have[ing] consistent outlets for the community to engage us regardless of changes in leadership. " Here, "us" refers to internal staff rather external contacts such as mayor or city council. Both P8 and P13 selected technologies that would facilitate more frequent and regular contact from within their respective entities: P8 thought staff use of 'text messaging' would be a good way to have casual conversations while P13 chose 'blogs' and 'social media' to remain in contact with communities over the duration of planning processes.

P11's focus was on how to preserve visions throughout cycles of political regimes that unfold during the timeframe of master plans, "plans like these happen on a scale of time that ends up being in between regimes (not something that happens on an annual basis) - even the best plans etched in stone have the challenge of becoming someone's else vision... how do you work through that?" P11 selected the action 'managing expectations' which he described as making it clear to citizens that even after a planning process produces a vision - this vision is not self-fulling. Rather, 
ongoing work is needed to keep the vision alive through cycles of leadership. His choice of technology was 'website' but he wondered how to avoid the tendency for websites to become static repositories rather than an ongoing source of engagement capable of sustaining visions, "[websites] become artifacts of the past rather than a living breathing thing...like the plan itself."

The key affordance for this strategy is preservation; but rather than preservation in the sense of documenting the past statically - preservation is future orientated and dynamic. For P8 and P13, preservation was a matter of facilitating ongoing casual conversation and social interactions by increasing contact from internal leadership. Whereas for P11, preservation was aimed at sustaining engagement necessary to carry on the visions embodied in plans. Preserving institutional relationships addresses the barrier cycles of leadership by extending the focal point of institutional contact thus drawing away from overdependence on singular, transitory relationships by distributing where, how, and with whom does institutional contact occur. This has implications for trust in community engagement where interpersonal and institutional trust have complimentary yet distinct roles. Generally public officials tend to emphasize interpersonal trust. This was reflected during the workshop (and our previous work [12]) in an instance where P8 expressed difficulty in thinking about how technology could be used in the retaining stage remarking, "this is hard because trust is people to people." P11 added, "people don't trust institutions they trust people..." In the end, design will need to take care in how trust is mediated in community engagement; balancing support of trust in both its institutional and interpersonal forms [12].

\section{DISCUSSION}

This paper posed the question: how might design support trust in the relational aims of digital civics? Through our design based inquiry with public officials, we developed four strategies towards answering this question: historicizing engagement, focusing on experience, mediating expectations and preserving institutional relationships. These strategies are grounded in the work of community engagement from the point of view of public officials. This purview presents an opportunity and challenge for digital civics. The opportunity is in how we understand the perspective and needs of public officials within the context of digital civics. The challenge is that designing for present needs and practices does not align with the goals of digital civics that aim to transform civic interactions and confront established modes of neoliberal governance. Reconciling the challenge of designing for what is, instead of what might be, prompts us to ask a more fundamental question of digital civics: should digital civics provide tools and support for the work of community engagement as is - responding to user need, such as it were? Or, do we design tools that reflect what we expect of public officials and residents alike in the work of governance?
In the end, we are left with the situation that on one hand, the perspective from public officials tends to leave participation, democracy, and power relations in place; while on the other, buy-in and adoption of new technologies by public officials is key to the success and longevity of digital civics $[9,43,44]$. One possible bridge between these conflicting goals is by focusing on the common denominator-the need for trust. Trust underlies the relational aims of digital civics and is also vital to the work of community engagement [26,41]. However, as we have argued, trust's importance is implicit in digital civics but also under-theorized in terms of design guidelines. Moreover, the use of digital tools in the work of community engagement to support trust is limited $[12,26]$. For this reason, orientating digital civics around trust serves to align digital civics with the work of community engagement performed by public officials. Doing so means developing a better understanding of the affordances within the strategies developed in our workshops.

\section{History}

While design is inherently future orientated-supporting relationships in digital civics will need to actively engage history to be successful. To engage history, we mean the ways in which past experiences can be brought to bear on current systems and processes. In the civic space, this can be difficult as history is often linked to inequity, injustice, broken promises, and ultimately distrust.

Digital civics has provided several examples we can draw from history to productively build relations between different constituencies. For instance, Crivellaro et al [16] explored how history of place was fundamental to the design of technologies to solicit oral history and build relations between past and future residents of public housing. The briefcase they designed was fitted with various audio recording and playback mechanisms and was passed from resident to resident, accumulating stories of place that set the stage for future engagement around the identity of the community. The key to success in Crivellaro's design intervention was by allowing residents agency in engaging history on their own terms, rather than accepting narratives developed from others.

In another example, Le Dantec and Fox's community historians project [22], local history was engaged through participatory design encounters to empower an underserved community through the creation of shared identity. In this case, sensing technology was used as a medium to explore how the community might further goals, communicate values, and utilize social capital. In these examples, agency and empowerment - both of which are vital to trust - were enabled through focusing on history in the design and use of digital media. These two examples point to ways in which history can be productive tethered by technology to establish a pathway to, and basis for trust. The challenge for design is moving these kinds of design interventions out of the community settings where they were developed, and into institutional settings where instrumental performance takes 
precedent over community building and affective experience. The concerns that P10 and P12 expressed during the workshop about technology's role in addressing historical breakdowns means that we need to find new ways of capturing, codifying, and sharing historical experiencenot just knowledge and data. One potential avenue is by focusing on agency and empowerment, both within the municipal workplace, and in relation to the municipal official and the community they serve.

\section{Experience}

Experience in the public sector is most often framed around customer service. One of the traits of neoliberal governance is by directly adopting the private sector perspective of business and technology to improve experience by running government like a business and treating citizens as customers. Of course, improving the experience of government along these lines is important-there are elements of local government that are best modeled as service providers with customer-but the larger point is to not conflate the experience of receiving service from the government with the experience of participating in the decision-making processes of government. Recognizing the difference between private and public sector needs is especially important given that the methods applied to improving experience in the former can be fundamentally incompatible to the values of experience in the latter $[1,24]$.

In contrast, experience in digital civics is framed as "participative experiences [34]" that "emphasizes dialogue, reflexivity and mutual learning" [40]. A key quality of participative experiences is reconfiguring social relations in terms of the roles actors play and how these change through participation. Trust is developed gradually over these experiences by developing empathy and understanding"making visible what is invisible to the other" [34]. Overall, McCarthy and Wright suggest trust is both the means and ends of participative experience-with design enabling participation and then responding to the dialogue created within [34].

Participatory experience thus construed seems well suited to addressing the challenges with experience that arose during the workshop. However, there is a dissonance between how experience is viewed by public officials and how it is framed within the research agenda of digital civics. In digital civics, experience is both the means and ends in bringing about fundamental changes to services, processes, relationships, and ultimately power. In comparison, the perspective of experience of our participants was much more incremental and pragmatic - the assumption is one of working within the status quo, rather than creating something entirely new. The unwillingness to break from the familiar was clear in how the technology selections of workshop participants were fitted into existing processes and tuned to amplifying reach or collecting data. Unfortunately, focusing on experience in this manner would be insufficient to address the primary barrier of one-off engagement that worried our participants (and which contributed to troubled histories of interaction).

Ultimately, civic design needs a middle ground. A potential example can be found in Johnson et al's community conversational platform [27]. Community conversational gamifies the experience of local consultation processes to encourage and structure conversations. The platform also featured an interface for searching and filtering data to support analysis by officials. In this way, the platform creates a participatory experience that can be used directly to support the work of community engagement. The second example is Sens-Us, which focused on the experience of citizen participation with surveys [23]. In order to spur more engagement with surveys (which are typically unappealing and tedious experience) Golsteijn et al explored how materiality and space could create a more enticing and enjoyable interaction. Promising in both of these examples is how creative, playful, and explorative experiences are wedded with the practical needs for gathering data and informing decision making that characterizes the work of community engagement performed by public officials.

In the end, research in digital civics is foregrounded by a commitment to experience, and to that end, provides several exemplar interventions $[15,16,23,30]$. However, the key question we raise here is how can these experiences achieve the other commitment of digital civics, "to support citizens becoming agents of democracy through technology and dialogue with public institutions that actualize public will" [46].

\section{Expectation}

At the most basic level, trust is a process of forming expectations. Thus, enabling trust is essentially about supporting how expectations are formed and maintained [38]. The challenge of supporting expectations arises from uncertainty and time; both of which are especially problematic in the work of community engagement. This was exemplified in the challenges with the barrier of 'speed of progress' that participants raised in the workshopengagement must continue and manage differing expectations about how quickly or how long something should, or does take.

Supporting expectations through design is perhaps the most straightforward of the four affordances. The most common form this affordance comes through interfaces like data dashboards and other associated visualizations of public data. Such systems are designed to share information and provide a common understanding and set of expectations of a process or service. While common, supporting expectations with open data and visualizations is not without its problems and limitations. For instance, McMillan et al discussed the problems public officials face when opening up data - the "messy realities of what it means to collect, curate, control, and disseminate data relating to the lives and practices of citizens" [35]. Creating and managing open data is a resource intense process that requires constant work of 
curating and translating across boundaries of accountability and influence [18]. Additionally, there is always the potential threat public officials face that the data they share could be used to subvert city functioning. Moreover, in addition to the problems McMillan identified, O'Hara's study of open data and transparency initiatives in the UK examines the interaction between open data and trust, pushing back against the simplistic determinism in much of the popular discourse surrounding the ability for open data to enable trust [39]. A key concern for O'Hara was that top down approacheswhere public institutions decide alone what to release and what not to-fail to be meaningful for citizens and thus fail to engender trust.

Using data dashboards and open data to manage expectations is also more bound to questions of accountability than to efforts to build trust in relationships. In fact, accountability is often a product and response to distrust, therefore necessitating the need for increased oversight. In this way, open data as means to engender trust is paradoxical-as society becomes increasingly more complex and interdependent, the ability to monitor, predict, and calculate is reduced, which explains the allure of efforts around smart cities where instrumentation and machine learning are deployed to manage these growing complexities. However, by applying complex systems to manage complex systems, we only increase uncertainty. Thus, ultimately the proliferation of data can,s in fact increase complexity and therefore risk which problematizes the process of forming positive expectations. In reality, people do not have the cognitive resources to perceive the multitude of vulnerabilities, so instead they trust (or rely) on institutions, others and systems [47].

A more appropriate approach to supporting expectations to sustain trust in digital civics can be drawn from Davis's work exploring participatory design in ambient persuasive technology [19]. Davis tries to solve the possibility of manipulation inherent in persuasive technology by introducing participatory design "by involving potential users in design helps to avoid some potential ethical issues with persuasive technology. Without participatory design, the designer stands outside of the community and intends to change the behavior of community members. With participatory design, the persuasive intent comes in part from community members who want to change the community's behavior from within." The possibility of manipulation Davis raises is also very relevant in supporting expectations generally and even more so if open-data is the method. In fact, both McMillan and O'Hara allude to the dangers of manipulation with open data-in terms of selecting, withholding data, scrubbing data and outright falsification. In comparison, participatory design as a method of supporting expectations would work by bringing people into the process of forming expectations - much the same as how Davis sought to create persuasive intent from within users. So rather than expectations being supported 'from afar' with open data and data visualizations which we have argued is just a way of increasing visibility of work being done by public officials - participatory design offers an alternative to support expectations 'from within' by working with public officials in formation of expectations. Thus, participatory methods of developing and opening up data present a promising approach to the affordance of expectations in digital civics. To this end, existing work around participatory data visualizations [11,17,20,21]—provide good examples of how this might pursued.

\section{Preservation}

On the whole, trust as a process is time consuming and arduous. Thus, preservation of relationships - which are the end products of the trust process-will always be important. On this point, digital civics and the needs of public officials are most aligned when it comes to preservation. For digital civics, preservation is implicit in creating participatory experiences in how these should focus on the durational quality of relationships to establish trust [34]. This necessitates extended ongoing encounters and a commitment to making lasting changes to relationships. Many of these elements McCarthy points out were also present in how preservation was approached in the workshop - supporting ongoing encounters, improving durational quality, and the commitment to lasting relationships revealed by P8, P11 and P13.

That being said, one important aspect of how preservation was pursed in the workshop was the distributive nature in the ways in which preservation was carried out-distributing where, how and with whom does institutional contact occur. This distributive aspect is both promising and problematic for trust. Bosman has recently detailed how the impact of technology on trust in society is tangled by how digital technology's fundamental impact on trust is distributive: trust becomes proliferated across systems, platforms and infrastructures [7]. A good example of distributive trust in digital civics is the CrowdMemo platform by Balestrini et al[3]. The platform was a socio-technical system for generating and circulating microdocumentaries in order to help preserve local heritage in a rural town. A key factor in the success of CrowdMemo was in how it distributed interactions across several different classes of relationships throughout the community. In this regard, the CrowdMemo project was an exemplar display of preservation in HCI.

On the other hand, distributive trust as means of achieving preservation is not without its problems. While in the past trust was centralized in institutions - through leaders or key officials (as was discussed in the workshop)-Bosman argues that distributive trust weakens institutional trust. This in turn reverberates to how trust operates interpersonally; trust is ultimately the product of interpersonal relationships as well as institutional which are intertwined in such a manner that, "trust cannot be fully understood and studied exclusively on either the psychological level or on the institutional level, because it so thoroughly permeates both" [32]. Ultimately, the take-away here is designing for 
preservation should be careful to consider the interrelated nature of both forms of trust.

\section{CONCLUSION}

In order to support trust in digital civics, we developed four strategies: historicizing engagement, focusing on experience, mediating expectations and preserving institutional relationships. These strategies are derived from the relationships between public officials and the citizens they work to engage. While digital civics has used as a point of departure the community perspective and experience, here we add balance by working from the institutional side. Thus, this work expands the design space by addressing a facet of digital civics that has gone under-studied: how design could approach creation of tools to support the work of community engagement performed by public officials. To this end, the four affordances we discussed provide a useful starting point to orientate future design interventions.

\section{ACKNOWLEDGMENTS}

We are grateful to our partners with the City of Atlanta. This project was supported in part by the NSF under grant IIS1524380 .

\section{REFERENCES}

1. Mariam Asad, Christopher A. Le Dantec, Becky Nielsen, and Kate Diedrick. 2017. Creating a Sociotechnical API. In Proceedings of the 2017 CHI Conference on Human Factors in Computing Systems - CHI '17, 2295-2306. https://doi.org/10.1145/3025453.3025963

2. Mariam Asad and Christopher A Le Dantec. 2015. Illegitimate Civic Participation: Supporting Community Activists on the Ground. In CSCW' 15: Proceedings of the 18th ACM Conference on Computer Supported Cooperative Work \& Social Computing, 1694-1703.

3. Mara Balestrini, Jon Bird, Paul Marshall, Alberto Zaro, and Yvonne Rogers. 2014. Understanding Sustained Community Engagement: A Case Study in Heritage Preservation in Rural Argentina. Proceedings of the SIGCHI Conference on Human Factors in Computing Systems: 2675-2684. https://doi.org/10.1145/2556288.2557323

4. Shakuntala Banaji and David Buckingham. 2013. The Civic Web. MIT Press.

5. Bernard Barber and Diego Gambetta. 1992. Trust: Making and Breaking Cooperative Relations. Contemporary Sociology $\quad 21, \quad 401$. https://doi.org/10.2307/2076328

6. a. Borning, B. Friedman, Janet L. Davis, and P. Lin. 2005. Informing Public Deliberation: Value Sensitive Design of Indicators for a Large-Scale Urban Simulation. Proceedings of the ECSCW 2005 European Conference on Computer-Supported Cooperative Work, September: 449-468. https://doi.org/10.1007/1-4020-4023-7

7. Rachel Botsman. 2017. Who can you trust?: how technology brought us together: and why it could drive us apart. Penguin UK: Kindle Edition.

8. Harry C Boyte. 2010. Everyday Politics. University of Pennsylvania Press.

9. Aurélien Buffat. 2015. Street-Level Bureaucracy and EGovernment. Public Management Review 17, 1: 149161. https://doi.org/10.1080/14719037.2013.771699

10. Pew Research Center. 2015. Beyond Distrust: How Americans View Their Government. https://doi.org/10.1017/CBO9781107415324.004

11. Rachel Clarke, Peter Wright, Madeline Balaam, and John Mccarthy. 2013. Digital portraits: Photo-sharing after domestic violence. Proc. CHI '13: 2517-2526. https://doi.org/10.1145/2470654.2481348

12. Eric Corbett and Christopher A Le Dantec. 2018. Going the Distance: Trust Work for Citizen Participation. In Proceedings of the 2018 CHI Conference on Human Factors in Computing Systems - CHI '18.

13. Eric Corbett and Christopher Le Dantec. The Problem of Community Engagement : Disentangling the Practices of Municipal Government. In Proceedings of the 2018 CHI Conference on Human Factors in Computing Systems CHI' 18 .

14. Clara Crivellaro, Rob Comber, J Bowers, Peter C Wright, and Patrick Olivier. 2014. A Pool of Dreams: Facebook, Politics and the Emergence of a Social Movement. In CHI '14: Proceedings of the 32nd annual ACM conference on Human factors in computing systems, 3573-3582.

15. Clara Crivellaro, Rob Comber, Martyn Dade-Robertson, Simon J. Bowen, Peter Wright, and Patrick Olivier. 2015. Contesting the city: enacting the pollitical through digitally supported urban walks. $\mathrm{CHI}$ '15: Proceedings of the 33rd Annual ACM Conference on Human Factors in Computing Systems: 2853-2862. https://doi.org/10.1145/2702123.2702176

16. Clara Crivellaro, Alex Taylor, Vasillis Vlachokyriakos, Rob Comber, Bettina Nissen, and Peter Wright. 2016. Re-Making Places: HCI,'Community Building'and Change. In Proceedings of the 2016 CHI Conference on Human Factors in Computing Systems, 2958-2969.

17. Catherine D'Ignazio and Lauren F Klein. 2016. Feminist data visualization. In Workshop on Visualization for the Digital Humanities (VIS4DH), Baltimore. IEEE.

18. Christopher a Le Dantec and W Keith Edwards. 2010. Across Boundaries of Influence and Accountability: The Multiple Scales of Public Sector Information Systems. Proceedings of the SIGCHI Conference on Human Factors in Computing Systems: 113-122. https://doi.org/10.1145/1753326.1753345

19. Janet Davis. 2009. Early experiences with participatory design of ambient persuasive technology. In CHI'09: Workshop on defining the role of HCI in the challenges of sustainability, 119-128. 
20. Carl DiSalvo, Jeff Maki, and Nathan Martin. 2007. Mapmover: a case study of design-oriented research into collective expression and constructed publics. Proc. CHI 2007:

1249-1252. https://doi.org/10.1145/1240624.1240813

21. Carl DiSalvo, Illah Nourbakhsh, David Holstius, Ayça Akin, and Marti Louw. 2008. The Neighborhood Networks project: a case study of critical engagement and creative expression through participatory design. In Proceedings of the Tenth Anniversary Conference on Participatory Design 2008, 41-50.

22. Sarah Fox and Christopher A Le Dantec. 2014. Community Historians: Scaffolding Community Engagement through Culture and Heritage.

23. Connie Golsteijn, Sarah Gallacher, Licia Capra, and Yvonne Rogers. 2016. Sens-Us. Proceedings of the 2016 ACM Conference on Designing Interactive Systems - DIS '16: 39-49. https://doi.org/10.1145/2901790.2901877

24. Eric Gordon and Stephen Walter. 2016. Meaningful Inefficiencies: Resisting the Logic of Technological Efficiency in the Design of Civic Systems. Civic Media: Technology, Design, Practice: 243.

25. Russell Hardin. 1999. Do we want trust in government? Democracy and trust: 22-41.

26. Mike Harding, Bran Knowles, Nigel Davies, and Mark Rouncefield. 2015. HCI, Civic Engagement \& Trust. Proceedings of the 33rd Annual ACM Conference on Human Factors in Computing Systems - CHI '15: 28332842. https://doi.org/10.1145/2702123.2702255

27. Ian G Johnson, Alistair Mcdonald, Jo Briggs, Jennifer Manuel, Karen Salt, Emma Flynn, and John Vines. 2017. Community Conversational : Supporting and Capturing Deliberative Talk in Local Consultation Processes.

28. Jonghyuk Jung, Eun-young Ko Songyi, Han Chang, Won Lee, Juho Kim, and Jihee Kim. 2016. BudgetMap: Engaging Taxpayers in the Issue-Driven Classification of a Government Budget. 1028-1039.

29. Juho Kim, Eun-young Ko, Jonghyuk Jung, Chang Won Lee, Nam Wook Kim, and Jihee Kim. 2015. Factful: Engaging Taxpayers in the Public Discussion of a Government Budget. Proceedings of the ACM CHI'15 Conference on Human Factors in Computing Systems 1: 2843-2852. https://doi.org/10.1145/2702123.2702352

30. Matthias Korn and Jon Back. 2012. Talking it further: from feelings and memories to civic discussions in and about places. Proceedings of the 7th Nordic Conference on Human-Computer Interaction: Making Sense Through Design: 189-198. https://doi.org/10.1145/2399016.2399046

31. Charles H Levine. 2015. Citizenship and Service Delivery. The age of direct citizen participation 44: 78 .

32. J David Lewis and Andrew Weigert. 1985. Trust as a
Social Reality. Source: Social Forces 63, 4: 967-985. https://doi.org/10.1093/sf/63.4.967

33. Niklas Luhmann. 1979. Trust and Power. Cooperation without Trust 8: 208.

34. John McCarthy and P Wright. 2015. Taking [A]part. MIT Press.

35. Donald McMillan, Arvid Engström, Airi Lampinen, and Barry Brown. 2016. Data and the City. Proceedings of the 2016 CHI Conference on Human Factors in Computing Systems - CHI '16: 2933-2944. https://doi.org/10.1145/2858036.2858434

36. Matthew B Miles, A Michael Huberman, and J Saldana. 1984. Qualitative data analysis: A sourcebook. Beverly Hills.

37. Guido Mollering. 2001. The Nature of Trust: From Georg Simmel to a Theroy fo Expectation, Interpertation ad Suspension. Sociology 35, 2: 403-420.

38. Guido Möllering. 2006. Trust: Reason, routine, reflexivity. Emerald Group Publishing.

39. Kieron O'Hara. 2012. Transparency, open data and trust in government. Proceedings of the 3rd Annual ACM Web Science Conference on - WebSci '12: 223-232. https://doi.org/10.1145/2380718.2380747

40. Patrick Olivier and $\mathrm{P}$ Wright. 2015. Digital civics: Taking a local turn. Interactions 22, 4: 61-63. https://doi.org/10.1145/2776885

41. Simon Parker, Phil Spires, Faizal Farook, and Melissa Mean. 2008. State of Trust. How to Build better Relationships between Councils and the Public. Demos, London.

42. Pew Research Center. 2015. Beyond Distrust: How Americans View Their Government. https://doi.org/10.1017/CBO9781107415324.004

43. Julie Simon, Theo Bass, Victoria Boelman, and Geoff Mulgan. 2017. NESTA Digital Democracy: the tools transforming political engagement.

44. Jon Sotsky and Jonathan Kartt. 2018. Scaling Civic Tech: Paths to a Sustainable Future.

45. Eran Vigoda-Gadot and Shlomo Mizrahi. 2014. Managing democracies in turbulent times: Trust, performance, and governance in modern states. https://doi.org/10.1007/978-3-642-54072-1

46. Vasillis Vlachokyriakos, Clara Crivellaro, Christopher A Le Dantec, Eric Gordon, Pete Wright, and Patrick Olivier. 2016. Digital Civics. In Proceedings of the 2016 CHI Conference Extended Abstracts on Human Factors in Computing Systems - CHI EA '16 (CHI EA '16), 10961099. https://doi.org/10.1145/2851581.2886436

47. Mark E Warren. 1999. Democracy and trust. Cambridge University Press. 